\title{
Expression of the Activating Transcription Factor 3 Prevents c-Jun N-Terminal Kinase-Induced Neuronal Death by Promoting Heat Shock Protein 27 Expression and Akt Activation
}

\author{
Saya Nakagomi, ${ }^{1}$ Yasuhiro Suzuki, ${ }^{1,2}$ Kazuhiko Namikawa, ${ }^{1}$ Sumiko Kiryu-Seo, ${ }^{1}$ and Hiroshi Kiyama ${ }^{1}$ \\ ${ }^{1}$ Department of Anatomy and Neurobiology, Osaka City University, Graduate School of Medicine, Osaka 545-8585, Japan, and ${ }^{2}$ First Department of \\ Medicine, Asahikawa Medical College, Asahikawa, Hokkaido, 078-8510 Japan
}

\begin{abstract}
Activating transcription factor 3 (ATF3) is induced and functions both as a cellular response to stress and to stimulate proliferation in multiple tissues. However, in the nervous system ATF3 is expressed only in injured neurons. Here we reveal a function of ATF3 in neurons under death stress. Overexpression of ATF3 by adenovirus inhibits the mitogen-activated kinase kinase kinase 1 (MEKK1)-c-Jun N-Terminal Kinase (JNK)-induced apoptosis and induces neurite elongation via Akt activation in PC12 cells and superior nerve ganglion neurons. A DNA microarray study reveals that ATF3 expression and JNK activation induce expression of the heat shock protein 27 (Hsp27). Immunoprecipitation analysis and promoter assay for Hsp27 expression suggest that both ATF3 and c-Jun are necessary for transcriptional activation of Hsp27. Hsp27 expression significantly inhibits JNK-induced apoptosis as well as Akt activation in PC12 cells and superior cervical ganglion neurons. We conclude that the combination of ATF3 and c-Jun induces the anti-apoptotic factor Hsp27, which directly or indirectly activates Akt, and thereby possibly inhibits apoptosis and induces nerve elongation. Our results suggest that ATF3- and c-Jun-induced Hsp27 expression is a novel survival response in neurons under death stress such as nerve injury.
\end{abstract}

Key words: nerve regeneration; neurite elongation; cell death; ATF; c-Jun; motor neuron

\section{Introduction}

After nerve injury, an injured neuron initiates an organized cascade of molecular expression to promote survival and regeneration (Fawcett and Geller, 1998), and a failure or lack of the expression of some molecules leads to death of the neurons (Honma et al., 2002). This organized expression might be regulated by initial factors such as transcription factors, which regulate multiple gene expressions. The immediate-early genes could be the initial factors that promote a response to stress stimuli such as nerve injury. Of the transcription factors expressed in response to nerve injury, activating transcription factor 3 (ATF3) and c-Jun, members of the cAMP response element-binding protein (CREB)/ATF family transcription factors, are particularly intriguing (Hai et al., 1989, 1999; Herdegen et al., 1997; Tsujino et al., 2000). ATF3 is considered to be a nerve injury marker because it is not normally found in neuronal cells but is highly expressed in response to nerve injury (Takeda et al., 2000; Tsujino et al., 2000). ATF3 is also known as a stress-inducible gene (Liang et al., 1996; Hai et al., 1999) and a transcriptional repressor (Chen et al., 1994). ATF3 binds to the ATF/CRE site, and its transcriptional activity differs according to its counterpart (Chen et al., 1994). The ATF3 homodimer is known to function as a repressor, whereas

\footnotetext{
Received Dec. 31, 2002; revised April 9, 2003; accepted April 9, 2003.

This work was supported in part by a Grant-in-Aid for Scientific Research from the Ministry of Education, Science, and Culture, Ministry of Health and Welfare, Japan. S.N. is a fellow of the Japan Society for the Promotion of Science. We are grateful to Dr. M Tohyama for encouragement. We thank for Dr. Uoshima for rat Hsp27 promoter.

Correspondence should be addressed to Dr. Hiroshi Kiyama, Department of Anatomy, Osaka City University Graduate School of Medicine, 1-4-3 Asahimachi, Abenoku, 0saka 545-8585, Japan. E-mail: kiyama@med.osakacu.ac.jp.

Copyright $\odot 2003$ Society for Neuroscience $\quad$ 0270-6474/03/235187-10\$15.00/0
}

the heterodimer, for instance in combination with c-Jun, functions as an activator of specific promoters in non-neuronal cells (Hsu et al., 1992; Hai and Hartman, 2001). c-Jun, which is another member of the CREB/ATF family, is also known as a stress-inducible gene in both neuronal and non-neuronal cells. c-Jun is activated by c-Jun $\mathrm{N}$-terminal kinase/stress-activated protein kinase (JNK/SAPK), which is in the MAP kinase superfamily and induces apoptosis in many types of cells, including neurons (Xia et al., 1995; Herdegen et al., 1997). JNK/SAPK activity increases in superior cervical ganglion (SCG) neurons after NGF withdrawal, and this increase occurs before the cell death commitment point (Eilers et al., 1998). Furthermore, overexpression of an activated form of the mitogen-activated kinase kinase (MEK) kinase 1 ( $\triangle \mathrm{MEKK} 1)$, an upstream activator of the JNK pathway, induces apoptosis in PC12 cells via JNK activation. Although the activation of c-Jun is therefore considered a deathpromoting response, c-Jun activation does not necessarily lead to cell death in some cases, such as in nerve-injured motor neurons in which substantial expression of ATF3 is also observed (Tsujino et al., 2000). Because c-Jun can be a potent partner of ATF3, ATF3 may act as the key determinant of whether c-Jun activation leads to cell death or to survival. Here we demonstrate that the expression of ATF3 in c-Jun-activated PC12 and SCG cells, which are normally killed, promotes heat shock protein 27 (Hsp27) expression (Benn et al., 2002) and thereby rescues and promotes neurite elongation in those cells.

\section{Materials and Methods}

Animals. Neonate (3 d old) and adult (6 week old) Wistar rats were anesthetized with pentobarbital, and the right hypoglossal nerve was transected. Operated or sham-operated animals were killed under anesthesia. For in situ hybridization, the brains were removed 6 and $12 \mathrm{hr}$ and $1,3,5,7,14$, and $28 \mathrm{~d}$ after axotomy (three rats in each) and frozen on 
powdered dry ice. Sections (18 $\mu \mathrm{m}$ thick) were cut on a cryostat and mounted on 3-aminopropyltriethyoxysilane-coated slides. For RT-PCR analysis, the hypoglossal nuclei of 10 operated rats were dissected from the operated and normal sides and frozen in liquid nitrogen.

In situ hybridization and immunohistochemistry. The following cDNA fragments were isolated by RT-PCR used as probes: ATF3, 162-708 of M63282; ATF2, 1025-1725 of NM-031018; c-Jun, 440-1469 of X17163. These plasmids were linearized, and ${ }^{35} \mathrm{~S}$-labeled cDNA probes were prepared by in vitro transcription using T3 or T7 RNA polymerase (Promega, Madison, WI) and ${ }^{35}$ S-UTP(NEN DuPont, Natick, MA). In situ hybridization was performed as described by Nakagomi et al. (1999). For immunohistochemical studies, rat brains were fixed in Zamboni's fixative ( 0.1 м PB containing $2 \%$ paraformaldehyde and $0.2 \%$ picric acid) $3 \mathrm{~d}$ after hypoglossal nerve axotomy. Brains were sectioned $(18 \mu \mathrm{m})$, and anti-ATF3 polyclonal antibody (1:2000; Santa Cruz Biotechnology, Santa Cruz, CA), anti-phospho c-Jun polyclonal antibody (1:1000; New England Biolabs, Beverly, MA), and anti-phospho ATF2 polyclonal antibody (1:1000; New England Biolabs) were used.

Construction of adenoviral vectors. Recombinant adenoviral vectors were constructed in the following manner. The cDNA fragments comprising the entire coding regions for rat ATF3, rat Hsp27, 1624-2505 of mouse MEKK1 (L13103), JNK binding domain of JNK interacting protein (JIP)-1 (contains amino acids 127-281), and rat c-Jun (X17163) were isolated from rat brain cDNA by using PCR. After that, a c-Myc (ATF3 and $\triangle$ MEKK1), Flag tag (Hsp27), or hemagglutinin (HA) tag (c-Jun) sequence was fused to its $\mathrm{N}$ terminal by using PCR. c-Jun223NLS (1-223 of rat c-Jun fused to nuclear localization signal) was constructed according to Treier et al. (1994) and fused to HA tag sequence. cDNA clones were subcloned into pAxCALNLw Cre-lox P system-mediated expression cassette (Sato et al., 1998) as described below. The recombinant adenovirus vectors AxCALNLAMEKK1, AxCALNLATF3, and AxCALNLHSP27 were constructed by the COS-terminal protein complex (TPC) method (Miyake et al., 1996). Each expression cosmid cassette and EcoT22I-digested adenovirus DNA-TPC (Ad5dlX DNA-TPC) were cotransfected into human embryonic kidney (HEK) 293 cells, and the recombinant adenoviruses were generated by homologous recombination and amplified in HEK293 cells. Finally, high titered recombinant viral stocks were generated in HEK293 cells, purified by cesium gradient centrifugation (Kanegae et al., 1994), and stored at $80^{\circ} \mathrm{C}$ until use. The viral titers were determined by a plaque-forming assay in HEK293 cells. AxCANLacZ (Terashima et al., 1997) and AxCANCre (Kanegae et al., 1995) were kindly provided by Drs. I. Saito and Y. Kanegae (University of Tokyo, Tokyo, Japan).

Cell culture. PC12 cells were maintained in RPMI 1640 medium containing 5\% fetal bovine serum and 10\% horse serum. Sympathetic neurons from the SCG of 1-d-old Wistar rats were isolated and dissociated by incubation in $1 \%$ collagenase, followed by trituration through the tip. Cells were plated on collagen-coated dishes and cultured in Eagle's MEM (Nissui, Tokyo, Japan) containing 10\% fetal calf serum, 2 mm glutamine, penicillin-streptomycin, and $50 \mathrm{ng} / \mathrm{ml} \mathrm{NGF}$. The antimitotic agents $5 \mu \mathrm{M}$ BrdU were added. On the second day, medium was changed to DMEM/ F12 (Invitrogen, Carlsbad, CA) with N2 supplement (Invitrogen), 50 $\mathrm{ng} / \mathrm{ml} \mathrm{NGF}$, penicillin, and streptomycin (Invitrogen). Five days after plating, SCG neurons were infected with adenovirus at 50 multiplicities of infection for each virus.

Immunocytochemistry. Forty-eight hours after adenovirus infection, PC12 cells and SCG neurons were fixed with 4\% paraformaldehyde in PBS for 20 min, washed, and permeabilized with $0.2 \%$ Triton X-100 in PBS for 5 min. After a brief washing step, fixed ganglia were blocked with PBS containing $1 \%$ BSA for $1 \mathrm{hr}$ at room temperature. Primary antibody incubations were performed using anti-c-Myc monoclonal antibody (Roche, Basel, Switzerland) or anti- $\beta$-galactosidase antibody (ICN Biochemicals, Aurora, $\mathrm{OH}$ ) in PBS containing $1 \% \mathrm{BSA}$ for $14-16 \mathrm{hr}$ at $4^{\circ} \mathrm{C}$. The cells with primary antibodies were washed three times with PBS and then incubated with FITClabeled anti-mouse antibodies (1:250; Amersham Biosciences, Arlington Heights, IL) and phalloidin conjugated with Alexa 594 (Molecular Probes, Eugene, OR) for $1 \mathrm{hr}$ at room temperature for detection of primary antibodies. Nuclei of SCG neurons were visualized by including $10 \mu \mathrm{g} / \mathrm{ml}$ Hoechst 33342 (Roche) in the first PBS wash after the secondary antibody incubation.
Forty-eight hours after AxCAMycATF3 or LacZ infection, SCG ganglia were fixed with $4 \%$ paraformaldehyde in PBS for $2 \mathrm{hr}$ at room temperature, washed, and permeabilized with $0.2 \%$ Triton X-100 in PBS for 10 min. After blocking with PBS containing 1\% BSA, ganglia were incubated with antineurofilament mouse antibody from $2 \mathrm{H} 3$ hybridoma (1:500; Developmental Studies Hybridoma Bank, The Johns Hopkins University, Baltimore, MD) and anti-c-Myc antibody (1:500; Santa Cruz Biotechnology) for $24 \mathrm{hr}$ at $4^{\circ} \mathrm{C}$. Alexa 594-labeled anti-mouse antibodies (1:250; Molecular Probes) and Alexa 488-labeled anti-rabbit antibodies (1:250; Molecular Probes) were used as secondary antibodies. Finally, SCG was viewed on a Zeiss LSM510 laser confocal microscope, and neurite lengths were measured.

Western blotting. Protein from adenoviral-infected whole-cell extracts were separated by SDS-PAGE and blotted to polyvinylidene difluoride membrane. Membranes were blocked in PBS containing 0.05\% Tween 20 and $5 \%$ nonfat milk powder and incubated for $14-16 \mathrm{hr}$ at $4^{\circ} \mathrm{C}$ with primary antibody. The following antibodies were used as probes: antiphospho Akt polyclonal antibody (1:1000; New England Biolabs), antiAkt polyclonal antibody (Kitamura et al., 1998), anti-phospho extracellular signal-related kinase (ERK) polyclonal antibody (1:1000; New England Biolabs), anti-ERK polyclonal antibody (1:1000; New England Biolabs), anti-HA antibody (12CA5, 1:5000; Roche), and anti-Myc antibody (9E10, 1:5000; Roche). Subsequently, membranes were incubated with horseradish peroxidase-conjugated secondary antibody (1:5000; Amersham Biosciences) and visualized by an enhanced chemiluminescence system (Amersham Biosciences).

DNA microarray analysis. AxCAATF3- or AxCADMEKK1- and AxCAATF3-infected PC12 cells were homogenized, and total RNA was purified 48 after adenovirus infection. Twenty microliters of total RNA were converted to cDNA and labeled with Cy3 or Cy5 using Atlas Glass Fluorescent labeling kit (Clontech, Palo Alto, CA) according to the manufacturer's protocol. Microarray chips (Clontech) were incubated for 16 $\mathrm{hr}$ at $50^{\circ}$ with labeled probes. Chips were washed and scanned using BioChip analyzer GeneTAC LS IV (Genomic Solutions, Ann Arbor, MI). Obtained data were analyzed with GeneSpring v4.02 software (Silicon Genetics, Redwood City, CA).

Semiquantitive PCR. Total RNA was obtained from the adenoviralinfected cells or transected and normal hypoglossal nuclei and reversetranscribed with oligo dT primer using Superscript II (Invitrogen) according to the manufacturer's protocol. Aliquots from the RT reaction were used for PCR amplification using primer pairs ubiquitously expressing glyceraldehyde-3-phosphate dehydrogenase (GAPDH) as a control. The specific primers for the mRNA of rat Hsp27, Hsp70 and Hsp90 were used and amplified by PCR. The reaction products were electrophoretically separated on a $1 \%$ agarose gel and visualized by staining with ethidium bromide.

Transfection and reporter gene analysis. pGL3 luciferase reporter vector that contains conservative AP-1 or CRE motif or $\mathrm{rHsp} 27$ promoter (rHsp27 promoter vector was a gift from Dr. Uoshima, Niigata University, Niigata, Japan) was used. The mutant -678 sites of the Hsp27 promoter contained the sequence $5^{\prime}$-TGAAACGGT-3' (mutated nucleotides underlined) compared with wild-type $\mathrm{Hsp} 27$ promoter sequence 5'-TGACACTCT- ${ }^{\prime}$. Adenovirus-infected PC12 cells ( $12 \mathrm{hr}$ after infection) were transfected with luciferase reporter vector. Cells were lysed $224 \mathrm{hr}$ after transfection, and reporter gene expression was analyzed using the Dual Luciferase Reporter assay kit (Promega) according to the manufacturer's protocol.

In vitro protein synthesis and electrophoretic mobility shift assay. Nuclear extracts were prepared from adenovirus-infected PC12 cells. Double-stranded oligonucleotides were radiolabeled using Klenow Fragment (Takara) and ${ }^{32} \mathrm{P}-\mathrm{CTP}(\mathrm{New}$ England Nuclear) according to the manufacturer's protocol. Electrophoretic mobility shift assay (EMSA) reactions containing $5 \mu \mathrm{g}$ of nuclear extract, $1 \times 10^{4} \mathrm{cpm}$ of radiolabeled oligonucleotide (from -685 to -665 of the Hsp27 promoter, CCGGATCTGACACTCTCACA), $1 \mu \mathrm{g}$ of poly(dl/dC), $50 \mathrm{~mm} \mathrm{HEPES-KOH,}$ $\mathrm{pH} 7.8,250 \mathrm{~mm} \mathrm{KCl}, 5 \mathrm{~mm}$ EDTA, $\mathrm{pH} 8.0,25 \mathrm{~mm}_{\mathrm{MgCl}_{2}}$, and $50 \%$ glycerol in volume of $20 \mu \mathrm{l}$ were incubated at room temperature for 30 min. Where indicated, excess unlabeled competitor double-stranded oligonucleotide or $1 \mathrm{ml}$ of anti-ATF3 or anti-c-Jun antibody (Santa Cruz Biotechnology) was incubated with the nuclear extracts for $30 \mathrm{~min}$ at 
room temperature before the addition of the radiolabeled probe. The DNA-protein complexes were then electrophoretically resolved on $4 \%$ polyacrylamide gels. The dried gels were exposed to x-ray film.

Survival assay. To estimate the survival activity of each virus, PC12 cells quantified cell viability $48 \mathrm{hr}$ after adenovirus infection. SCG neurons were washed with NGF-free medium $24 \mathrm{hr}$ after adenovirus infection and incubated with NGF-free medium containing neutralizing antibody to $2.5 \mathrm{SNGF}$ (1:1000; Sigma). Then, $48 \mathrm{hr}$ after NGF withdrawal, quantitative determinations of surviving cells were made. For cell viability assay, a biochemical method using a highly water-soluble tetrazolium salt (WST-8, Nakalai Tesque, Kyoto, Japan) was used to determine the percentage ratio of surviving cells, following the manufacturer's protocol. For the histological identification of dying neurons after NGF withdrawal, nuclei of SCG neurons were stained by Hoechst 33342 (10 $\mu \mathrm{g} / \mathrm{ml}$; Roche).

Immunoprecipitation. Cells were homogenized in ice-cold TNE buffer (10 mm Tris-HCl, pH 7.8, 1\% NP40,0.15 M NaCl, 1 mm EDTA) and cleared by centrifugation. The protein concentration was determined using a Bio-Rad protein assay kit according to the manufacturer's instructions. Protein lysates were immunoprecipitated with antibodies specific for anti-ATF3 (Santa Cruz Biotechnology) or anti-c-Jun (Santa Cruz Biotechnology) antibody overnight and precipitated using protein G-Sepharose beads (Sigma). After overnight incubation with the beads, cell lysates were washed four times with lysis buffer, boiled for $5 \mathrm{~min}$, and subjected to electrophoretic and immunoblot analysis.

\section{Results}

ATF3 is expressed more strongly in injured motor neurons of adult rats

Although no expression of ATF3 mRNA was observed in any region of the normal adult rat brain (Fig. 1A), ATF3 mRNA was substantially induced in nerve-injured hypoglossal motor neurons of adult rat (Fig. $1 D, G$ ). The induction of ATF3 expression was confirmed by the appearance of the immunoreactivity in the nuclei of the injured motor neurons (Fig. 1J). Likewise, inductions of c-Jun mRNA and phospho-c-Jun immunoreactivity were observed in nerve-injured hypoglossal motor neurons of adult (Fig. $1 B, E, H, K)$. ATF3 and c-Jun upregulation occurred immediately $(6-12 \mathrm{hr})$ after nerve injury and continued over 4 weeks (Fig. 1P); however, similar induction was not found in ATF2, another family member (Fig. $1 C, F, I, L)$.

ATF3 and c-Jun mRNAs were also increased in axotomized neonatal rat, in which injured neurons gradually die (Fig. $1 M, N)$. Induction of ATF3 mRNA, however, was expressed more strongly in adult neurons compared with neonates after nerve injury, whereas the expression level of c-Jun mRNA appeared similar in adults and neonates in injured neurons (Fig. $1 Q)$. The basal level of c-Jun expression in adult neurons is low compared with neonates but increases after nerve injury to levels comparable with neonates.

\section{ATF3 prevents cell death and induces neurite elongation in JNK-activated PC12 cells}

If ATF3 is involved in nerve regeneration, ATF3 might also have a role in inhibition of cell death and neurite elongation. First, we investigated the role of ATF3 in cell death. Undifferentiated PC12 cells are known to die when the catalytic domain of MEKK1 ( $\triangle \mathrm{MEKK} 1)$ is overexpressed, which induces JNK activation in PC12 cells (Xia et al., 1995; Eilers et al., 1998). In fact, expression of $\triangle \mathrm{MEKK} 1$ in PC12 cells does activate JNK but not ERK and p38 (Fig. 2E-G). To examine the functional role of ATF3 in apoptosis, PC12 cells were infected with adenovirus overexpressing ATF3 (ad-ATF3) or adenovirus overexpressing $\triangle$ MEKK1 (ad$\Delta \mathrm{MEKK} 1$ ), or both. To examine whether the expression of proteins was comparable between single and double infections,
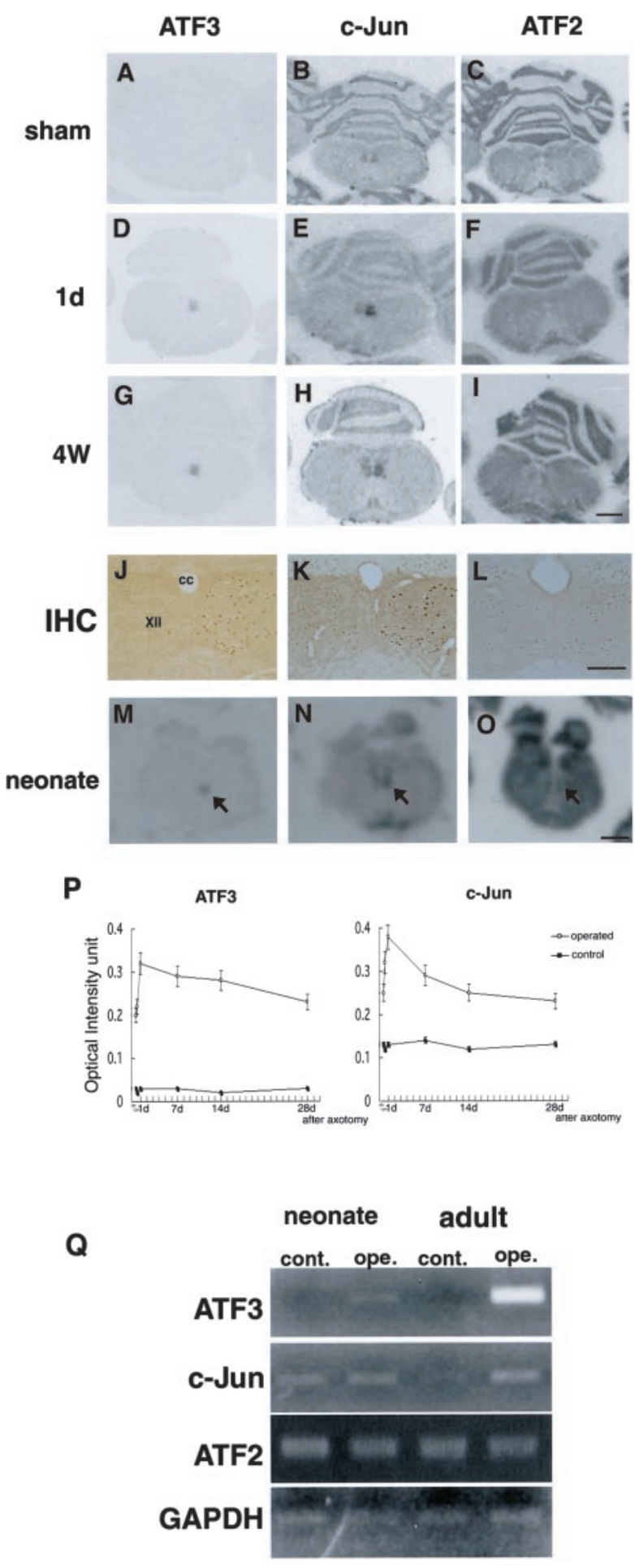

Figure 1. Expression of mRNA $(A-I, M-0)$ and protein ( $J-L)$ for ATF3, C-Jun, and ATF2 in hypoglossal nucleus $1 \mathrm{~d}$ after right hypoglossal nerve transection (right-hand side) displayed by in situ hybridization and immunohistochemistry (IHC). $A-L$ demonstrate results obtained from adult rat, whereas $M-0$ show those from neonate ( $3 \mathrm{~d}$ after birth). Arrows indicate injured side of hypglossal nuclei. Scale bars: $A-I, M-0,1 \mathrm{~mm} ; J-L, 200 \mu \mathrm{m}$. cc, Central canal; XII, hypoglossal nucleus. Note that in $M-0$ exposure was performed $2 \mathrm{~d}$ longer to visualize positive signals more clearly. $P$, Expression profile of ATF3 and c-Jun mRNA in both transection side $(O)$ and control side $(\square)$. Each point shows the average intensity of the positive signals and its SD ( $Q$ ) RT-PCR analysis of mRNA expression for ATF3, c-Jun, and ATF2 in control and operated hypoglossal nuclei $3 \mathrm{~d}$ after axotomy. cont., Control side; ope., operated side. Equivalent amounts of GAPDH are amplified from all samples, verifying standardization of conditions. 
Western blotting analysis was performed (Fig. 2A). In our experimental system, the expression levels of adenovirus-mediated proteins were similar between single and double infections. The overexpression of ATF3 alone did not affect on the survival of PC12 cells (Fig. 2B) and did not change the activity of ERK, JNK, and p38 (Fig. $2 E-G) . \Delta$ MEKK1 overexpression significantly activated JNK but not ERK or p38 (Fig. 2E-G) and led to considerable PC12 cell death (Fig. 2B). However, simultaneous expression of ATF3 and $\triangle$ MEKK1 canceled $\triangle \mathrm{MEKK} 1$-induced cell death, and even normal cell death under ordinary culture conditions, as well as viral infection-induced cell death, was significantly suppressed (Fig. 2 B). Interestingly, the simultaneous expression of ATF3 and $\triangle \mathrm{MEKK} 1$ induced neurite outgrowth in undifferentiated PC12 cells without growth factor application (Fig. 2C). This neurite outgrowth was not seen when either ATF3 or $\triangle$ MEKK1 was expressed alone (Fig. 2C).

In terms of intracellular signaling for survival and neurite formation in PC12 cells, activation of either the ERK or Akt pathway is plausible (Creedon et al., 1996; Namikawa et al., 2000). To examine whether these kinases are activated during inhibition of cell death and neurite elongation by ATF3 expression and JNK activation, immunoblot analysis was performed using anti-phospho-specific antibodies for Akt, ERK, and p38. The simultaneous expression of ATF3 and $\triangle \mathrm{MEKK} 1$ activated Akt but not ERK or p38 (Fig. $2 \mathrm{~F}-H$ ).

\section{ATF3 protects SCG neurons against apoptosis and induces neurite outgrowth after NGF deprivation}

When sympathetic neurons are deprived of NGF, the JNK-c-Jun pathway is activated and induces cell death (Fig 3I) (Eilers et al., 1998). Therefore we next examined whether ATF3 could inhibit NGF withdrawal-induced death. SCG neurons were infected with ad-ATF3 and incubated with NGF-free medium supplemented with neutralizing antiNGF antibody. The survival of neurons infected with ad-ATF3 was enhanced compared with neurons infected with the LacZ-overexpressing adenovirus in the WST-8 assay (Fig. $3 A a)$. Furthermore, the ratio of cells having pyknotic nuclei, which is an apoptotic feature, among infected cells (c-myc positive) was counted. This histological assay demonstrated more significant rescue activity in ATF3-expressing cells than in $\beta$-galactosidase-expressing controls (Fig. $3 A b$ ). To examine whether ATF3 can promote neurite elongation of SCG neurons, organ culture of SCG was used. In the organ culture,

F
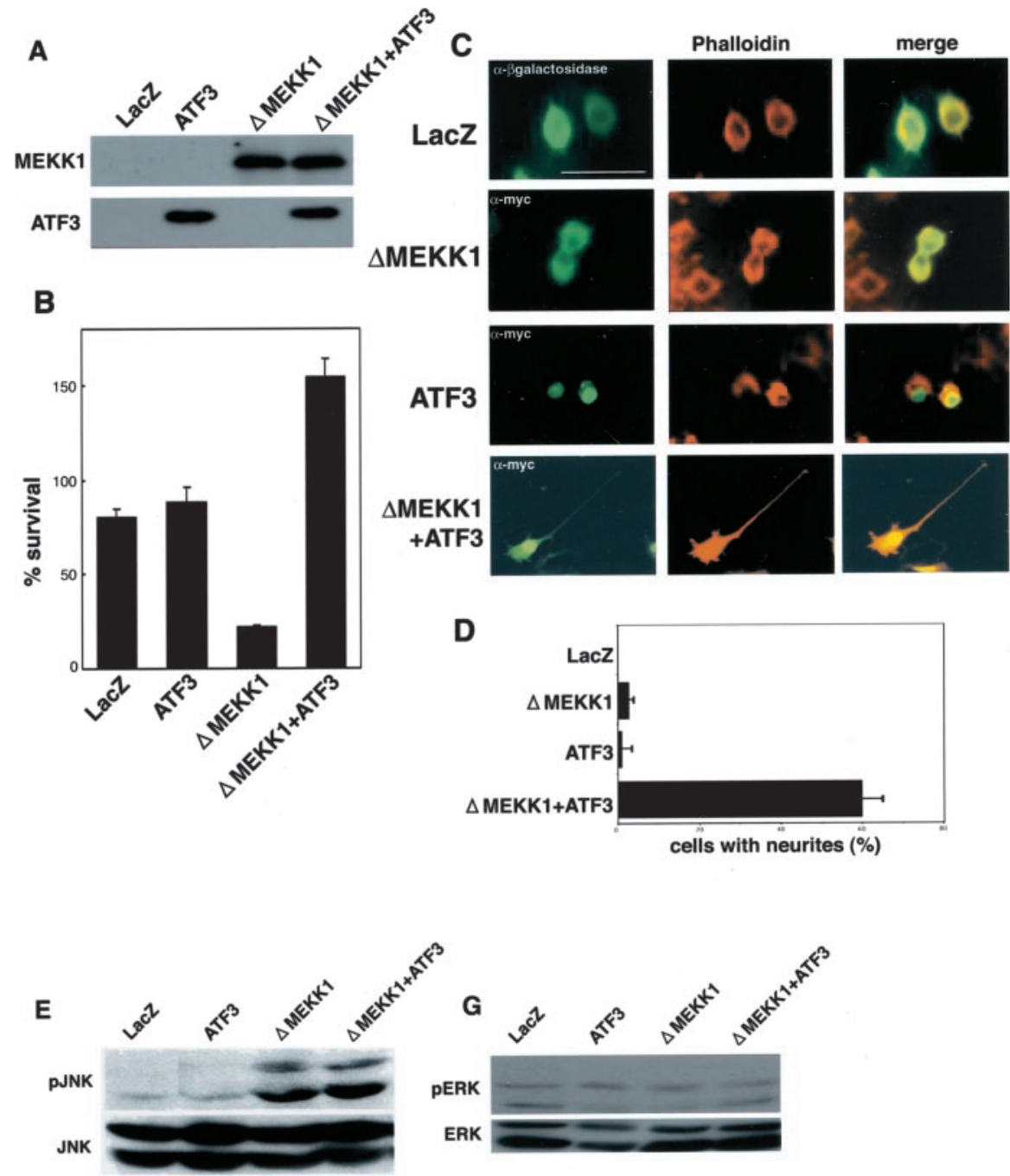

Figure 2. ATF3 expression rescues $\mathrm{PC1} 2$ cells from $\triangle$ MEKK1-induced cell death and promotes neurite outgrowth. $A$, Expression of adenovirus-induced protein in infected PC12 cells. ATF3 and $\triangle$ MEKK1 were detected by Western blotting analysis using antic-myc antibody. Note that similar levels of expression are achieved in both single and double infections. $B$, Viability of PC12 cells 48 hr after adenovirus infection compared with uninfected PC12 cells. Viability of cells without adenovirus infection was defined as $100 \%$. Each column represents the average of values from four different experiments. C, Morphology of adenovirus-infected PC12 cells. Forty-eight hours after adenovirus infection, the cells were fixed, and infected cells were detected with anti- $\beta$-galactosidase antibody (LacZ) or anti-c-myc antibody (ATF3 and $\triangle$ MEKK1) (green). Phalloidin conjugated with Alexa594 was used to visualize the cell shape. Scale bar, $20 \mu \mathrm{m}$. D, Quantification of neurite outgrowth. The percentage of the cells with neurite exceeding twice the cell body diameter length among the infected cells is shown. $E-H$, Immunoblot analysis of PC12 cells after adenovirus infection. In PC12 cells, phosphorylation of JNK was increased after $\triangle$ MEKK1 infection, whereas phosphorylation of ERKs and p38 was not changed. Phosphorylation of Akt was increased when ad-ATF3 and ad- $\Delta$ MEKK1 were coinfected. The expression levels of ERK and Akt are not altered by the viral infections. overexpression of ATF3 promoted dramatic neurite elongation of SCG neurons under the condition of JNK activation by NGF deprivation (Fig. $3 B-D, H$ ), whereas LacZ expression did not show remarkable neurite extension (Fig. $3 E-G, H$ ). As mentioned previously, NGF deprivation induced dramatic activation of JNK (Fig. 3I) as seen in PC12 cells; Akt but not ERK was significantly phosphorylated in NGF-deprived and ATF3 overexpressed SCG neurons (Fig. 3J,K). 

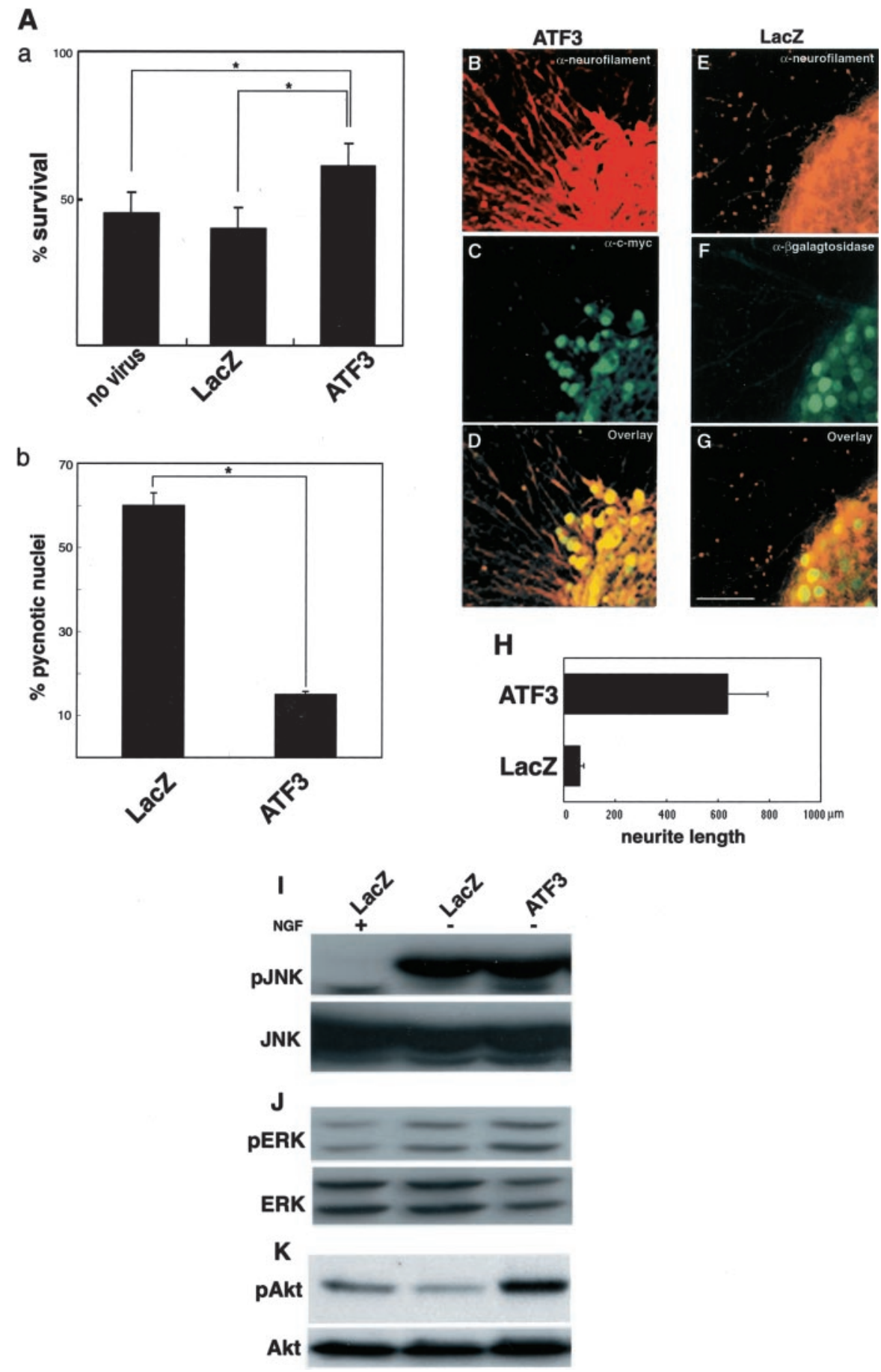

Figure 3. ATF3 expression rescues SCG neurons from NGF deprivation-induced neuronal death and elongates neurite. $A, a$, Viability of adenovirus-infected SCG neurons $48 \mathrm{hr}$ after NGF withdrawal. Viability of SCG neurons cultured with NGF medium was defined as $100 \%$. Each column represents the average of values from four different experiments. ${ }^{*} p=0.01$ (Student's $t$ test). $b$, NGF was withdrawn $24 \mathrm{hr}$ after adenovirus infection, and another $24 \mathrm{hr}$ later, nuclear morphology was visualized with Hoechst 33342. The ratio of cells having pyknotic nuclei among adenovirus-expressing cells visualized by anti-c-myc or anti- $\beta$ galactosidase antibody was measured. ${ }^{*} p=0.01$ (Student'st test). $B-G$, Morphology of adenovirus-infected SCGs ( $B-D$, ad-ATF3; $E-G$, ad-LacZ). After being cultured without growth factors for $5 \mathrm{~d}$, the cells were fixed and stained with anti-neurofilament antibody (red). Anti-c-Myc antibody and anti- $\beta$-galactosidase antibody were used to detect adenovirus-infected neurons (green). Scale bar, $100 \mu \mathrm{m}$. H, Neurite length of infected cells was measured from the organ cultured edge of SCG. I-K, Immunoblot analysis for the expressions of pJNK, pERK, and pAkt in SCG neurons after the adenovirus infection. Twenty-four hours after adenovirus infection, SCG neurons were refed with + NGF or - NGF medium and incubated for 1 more day. When NGF was depleted, JNK activation (increase of pJNK level) was seen. ATF3 expression under the condition of - NGF induced Akt activation (pAkt) but not $\operatorname{ERK}(J, K)$.

\section{ATF3 expression induces Hsp27} expression downstream of JNK In studies of PC12 and SCG cells, simultaneous expression of ATF3 and $\triangle$ MEKK1 did demonstrate anti-apoptotic activities and neurite elongation. This may be attributable to the transcriptional activity of ATF3. To identify genes expressed by transcriptional activity of ATF3, we used DNA microarray analysis. We analyzed ATF3 overexpression in PC12 cells with or without JNK activation by $\triangle$ MEKK1. Comparison of expression patterns of adATF3-infected cells versus ad-ATF3 and ad- $\triangle$ MEKK1 demonstrated several candidate genes: $\sim 50$ genes demonstrated a more than fivefold increase in doubleinfected cells. The candidates were examined by in situ hybridization screening if these gene expressions were also upregulated in nerve-injured motor neurons. Among those candidates, the increase of Hsp 27 mRNA was the strongest and clearest; we then focused on Hsp27 for the following studies. In PC12 cells, ATF3 overexpression alone did not show any expression of Hsp27 mRNA, whereas adATF3- and ad- $\triangle$ MEKK1-infected PC12 cells demonstrated a marked increase of Hsp27 mRNA (Fig. 4A). A slight increase of Hsp27 mRNA was observed only in ad$\triangle \mathrm{MEKK} 1$-infected PC12 cells, but this increase was much less than with the double infections. Similarly in SCG neurons, NGF deprivation (JNK activation) and ATF3 expression significantly induced Hsp27 mRNA expression (Fig. 4A). As observed in PC12 cells, a slight increase of Hsp27 mRNA was seen when SCG neurons were deprived of NGF and activated JNK, but Hsp27 was dramatically upregulated after ad-ATF3 infection. To confirm that transcriptional activation by ATF3 was influenced by JNK, we used adenovirus vector overexpressing JNK binding domain of JIP-1 [JIP(JBD)], a scaffold protein that inhibits JNK activation and c-Jun phosphorylation (Dickens et al., 1997; Eilers et al., 2001; Tawadros et al., 2002). JNK inhibition diminished Hsp27 upregulation by ATF3 in both PC12 cells and SCG neurons (Fig. 4A). These results indicate that ATF3-induced transcriptional activation needs activation of JNK in PC12 cells and SCG neurons. Next, promoter activity of Hsp27 was examined by using rat Hsp27 promoter $(2.7 \mathrm{~kb})$. PC12 cells were transfected with the rHsp27 promoter combined with luciferase reporter gene ( $\mathrm{HHsp} 27-\mathrm{luc})$. The double infection of ad-ATF3 and ad$\triangle \mathrm{MEKK} 1$ to PC12 cells showed a substantial increase of promoter activity of Hsp27 

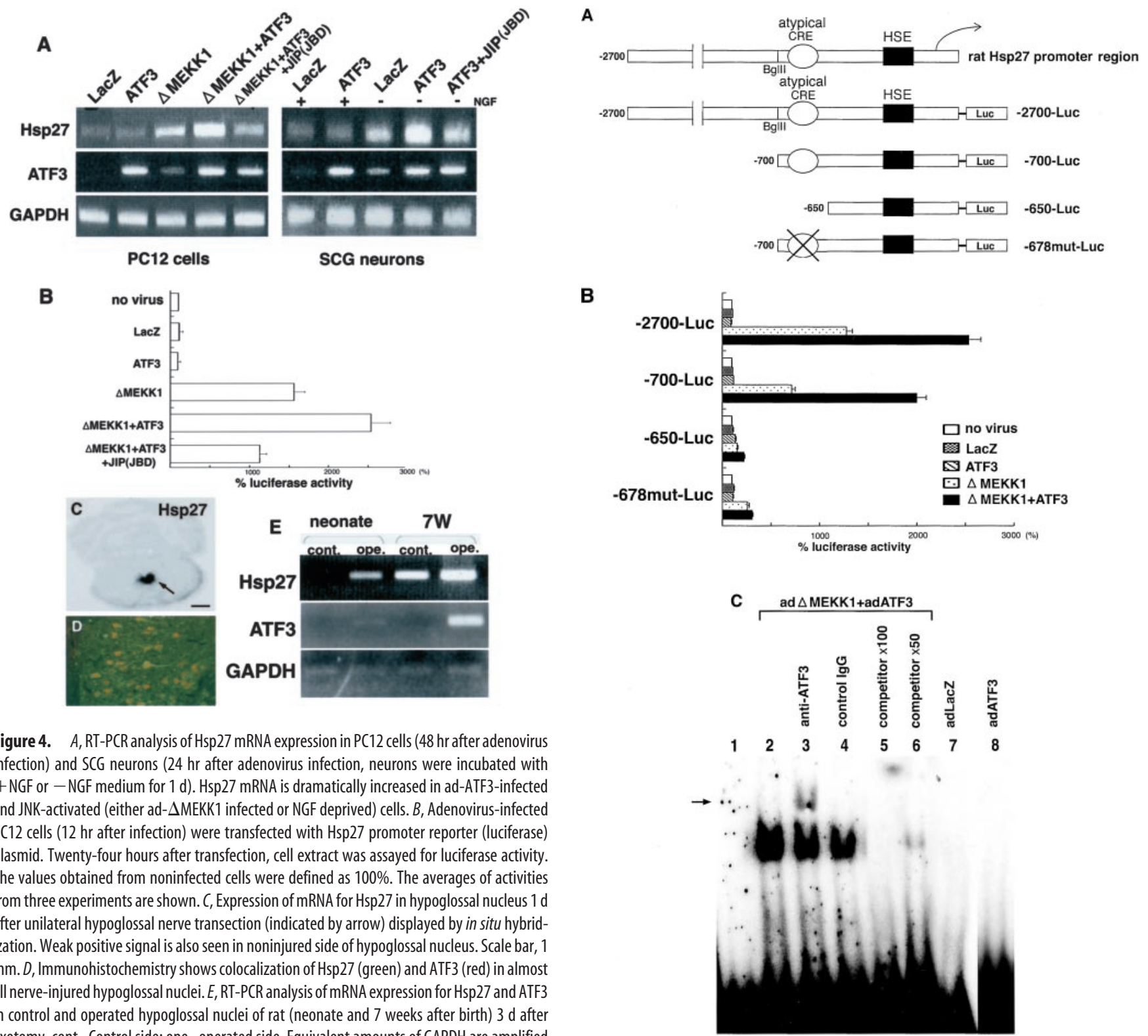

Figure 4. A, RT-PCR analysis of Hsp27 mRNA expression in PC12 cells (48 hr after adenovirus infection) and SCG neurons (24 hr after adenovirus infection, neurons were incubated with + NGF or - NGF medium for $1 \mathrm{~d}$ ). Hsp27 mRNA is dramatically increased in ad-ATF3-infected and JNK-activated (either ad- $\triangle$ MEKK1 infected or NGF deprived) cells. B, Adenovirus-infected PC12 cells (12 hr after infection) were transfected with Hsp27 promoter reporter (luciferase) plasmid. Twenty-four hours after transfection, cell extract was assayed for luciferase activity. The values obtained from noninfected cells were defined as $100 \%$. The averages of activities from three experiments are shown. C, Expression of mRNA for Hsp27 in hypoglossal nucleus $1 \mathrm{~d}$ after unilateral hypoglossal nerve transection (indicated by arrow) displayed by in situ hybridization. Weak positive signal is also seen in noninjured side of hypoglossal nucleus. Scale bar, 1 $\mathrm{mm} . \mathrm{D}$, Immunohistochemistry shows colocalization of Hsp27 (green) and ATF3 (red) in almost all nerve-injured hypoglossal nuclei. E, RT-PCR analysis of mRNA expression for Hsp27 and ATF3 in control and operated hypoglossal nuclei of rat (neonate and 7 weeks after birth) $3 \mathrm{~d}$ after axotomy. cont., Control side; ope., operated side. Equivalent amounts of GAPDH are amplified from all samples, verifying standardization of conditions.

than did the control and ad-ATF3-infected cells (Fig. 4B). Ad$\triangle \mathrm{MEKK} 1$-infected cells also demonstrated an increase of promoter activity, but the increase is lower than that of the doubleinfected cells. Consistent with RT-PCR, JIP(JBD) inhibited ATF3 transcriptional activity. JNK activation is necessary for upregulation of Hsp27 promoter by ATF3 (Fig. 4B). The similar induction of Hsp27 was observed in hypoglossal nerve-injured motor neurons and c-Jun expression, and phosphorylation was also induced in axotomized hypoglossal nucleus. These results suggest that similar gene regulation might exist in vivo. Although some level of Hsp27 mRNA expression was seen in the noninjured side of the hypoglossal nucleus, substantial upregulation of Hsp27 mRNA was observed in the nerve-injured hypoglossal nucleus (Fig. 4C). The cytoplasmic immunostaining for Hsp27 and nuclear immunostaining for ATF3 were simultaneously observed in all injured motor neurons (Fig. 4D). RT-PCR analysis also showed an intense mRNA expression of Hsp27 in the nerveinjured hypoglossal nucleus of adult rats but faint expression in that of neonate (Fig. $4 E$ ).

Figure 5. A, Constructs of Hsp27 promoter mutants. A series of $5^{\prime}$-deletion mutants and point mutant for CRE site of the Hsp27 promoter are constructed, and reporter genes [luciferase (Luc)] are attached downstream of these mutants. B, Adenovirus-infected PC12 cells ( $12 \mathrm{hr}$ after infection) were transfected with Hsp27 promoter reporter mutant plasmid. Twenty-four hours after transfection, cell extract was assayed for luciferase activity. The averages of activities from three experiments are shown. The values obtained from noninfected cells were defined as $100 \%$. C, Nuclear extracts were prepared from ad-ATF3 only (lane 8), ad- $\Delta$ MEKK1 + ad-ATF3 (lanes 2-6), and ad-LacZ only (lane 7) infected PC12 cells ( $48 \mathrm{hr}$ after infection), and equal amounts of protein $(2 \mu \mathrm{g})$ were used for gel mobility shift assay using atypical AP1 sequence of the Hsp27 promoter. The presence of anti-ATF3 antibody (lane 3) demonstrated the supershift (arrow), but not with control antibody (lane 4). Gel shift assay was also performed in the presence of 100 and $50 \times$ higher molar ratio of the nonlabeled atypical AP1 oligonucleotide (lanes 5,6$)$. Lane 1 shows probe only.

\section{ATF3 recognizes atypical CRE site in Hsp27 promoter}

Sequence analysis of the Hsp27 promoter revealed that an atypical CRE motif ( $5^{\prime}$-TGACACTCT-3') is located at -678 of the promoter. Promoter assay using $5^{\prime}$-deletion mutants or point mutants for the -678 site of the Hsp 27 gene promoter plasmids revealed that ATF3 had no effect on luciferase reporter activity without the atypical CRE motif located at -678 (Fig. 5A, B). These results indicate that ATF3 may preferentially bind to the -678 site 
A

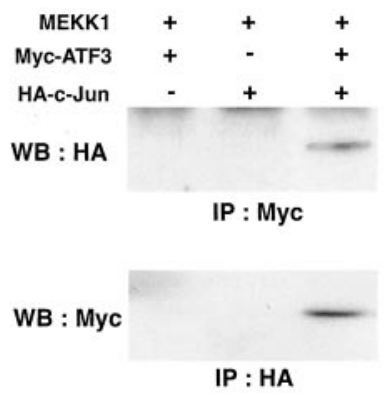

C

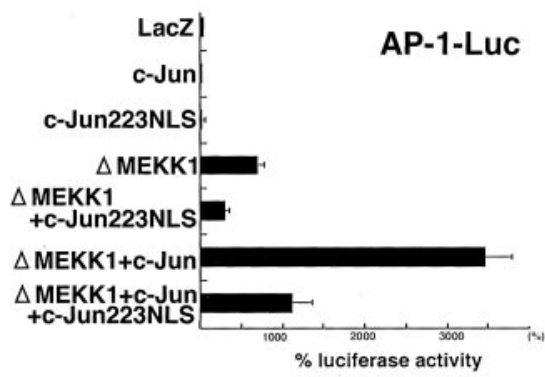

$\mathbf{E}$

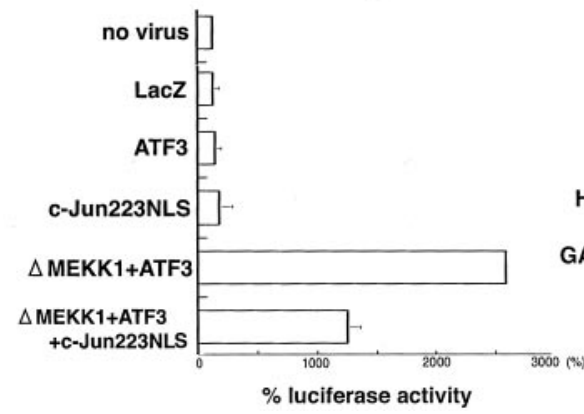

Figure 6. ATF3 binds to $\mathrm{C}-\mathrm{Jun}$ and activates $\mathrm{Hsp27}$ promoter and the transcription. A, Immunoprecipitation analysis shows that ATF3 binds to $c-J u n$ in PC12 cells. PC12 cells were infected with ad-ATF3 (c-Myc tagged) and adenovirus overexpressing c-Jun (ad-c-Jun, HA tagged). Forty-eight hours after infection, cells were lysed and immunoprecipitated using anti-HA antibody or anti-c-Myc antibody. B-D, Characterization of C-terminal truncated form of C-Jun (C-Jun223NLS), as a c-Jun dominant-negative form. B, C-terminal truncated form of C-Jun (C-Jun223NLS) suppresses the phosphorylation of endogenous C-Jun. Phosphorylation of endogenous $c-J u n$ is increased after ad $\triangle$ MEKK1 infection (arrow $a$ ), but its increase is suppressed in additional infection of adc-Jun223NLS. Arrow $b$ indicates phosphorylation of c-Jun223NLS ( $\sim 25 \mathrm{kDa}$ ). HA-tagged c-Jun223NLS was used in this analysis and detected by anti-HA antibody. C, D, A dominant-negative effect of C-Jun223NLS on promoters having conservative AP-1 ( $C$ ) and CRE (D) motifs. The adenovirus-infected PC12 cells (12 hr after infection) were transfected with luciferase (Luc) reporter vector, which contains conservative AP-1 or CRE motif. Twenty-four hours after transfection, cell extract was assayed for luciferase activity. The averages of activities from three experiments are shown. The values obtained from ad-LacZ-infected cells were defined as $100 \%$. E, C-terminal truncated form of C-Jun (C-Jun223NLS) diminishes $\triangle$ MEKK1- and ATF3-induced activity of Hsp27 promoter. Hsp27-Luc was transfected into PC12 cells together with plasmids expressing ATF3, $\triangle$ MEKK1, and c-Jun223NLS. The values obtained from noninfected cells were defined as 100\%. F, RT-PCR analysis of Hsp27 mRNA expression in PC12 cells (48 hr after adenovirus infection) and SCG neurons (incubated with + NGF or - NGF medium for $1 \mathrm{~d}, 24 \mathrm{hr}$ after adenovirus infection). Hsp27 mRNA upregulation by ATF3 was diminished when c-Jun223NLS was coexpressed.

and mediate the transcriptional activation of Hsp27. We further examined whether ATF3 could bind to this motif by EMSA analysis. Nuclear extracts from both ad-ATF3- and ad- $\triangle$ MEKK1infected PC12 cells were reacted with a typical CRE motif located at -678 . As expected, ATF3 bound the atypical CRE motif (Fig. $5 C$, lane 2) and supershifted with an anti-ATF3 antibody (Fig. 5C, lane 3, arrow). Nuclear extract from the ad-LacZ-infected PC12 cells failed to show specific complex formation with these same oligonucleotides (Fig. 5C, lane 7). These facts revealed that ATF3 could bind to the -678 site of the Hsp27 promoter and activate Hsp27 expression.

ATF3 binds to c-Jun, and the Cterminal truncated form of c-Jun downregulates Hsp27 mRNA expression and promoter activity Our results suggest that the anti-apoptotic activity of ATF3 is regulated by JNK. c-Jun is a major target of JNK, and the phosphorylation of c-Jun is a crucial step for JNK-induced cell death (Ham et al., 1995). Concurrently c-Jun is also activated in nerve-injured motor neurons (Herdegen et al., 1997), and its overexpression promotes neurite elongation in undifferentiated PC12 cells downstream of JNK (Leppa et al., 1998, 2001). This suggests that c-Jun may be implicated in the ATF3 function in neurons under cell death. Because c-Jun and ATF3 belong to the same bZip family and can form heterodimers (Hai and Curran, 1991), the ATF3 and c-Jun heterodimerization may be potentially important in promoting Hsp27 activity. We first examined whether ATF3 binds to c-Jun in PC12 cells infected with adenovirus expressing ATF3 and c-Jun. Immunoprecipitation analysis revealed that ATF3 could bind to c-Jun in PC12 cells (Fig. $6 A$ ). The same results were obtained without ad- $\triangle$ MEKK1 infection. To address the significance of c-Jun involvement in Hsp27 expression, the C-terminal truncated form of c-Jun (c-Jun223NLS), which is a potent c-Jun dominant-negative form, was examined (Leppa et al., 1998, 2001). The c-Jun223NLS inhibits c-Jun activity by competing with wild-type c-Jun. Overexpression of c-Jun223NLS causes decreases in wild-type c-Jun phosphorylation and transcriptional activation in AP-1 and CRE sites (Fig. 6B-D). We therefore examined promoter activity of Hsp27 by using c-Jun223NLS. Hsp27 promoter activity induced by ATF3 and JNK activation was significantly inhibited by c-Jun223NLS (Fig. 6E). The c-Jun223NLS suppressed Hsp27 mRNA induction in PC12 cells as well (Fig. $6 F$ ). Likewise, ATF3-induced expression of Hsp27 mRNA under the condition of NGF deprivation was completely suppressed by the c-Jun223NLS in SCG neurons. These results suggest that ATF3 possibly binds to the Hsp27 promoter in association with c-Jun and induces the expression of Hsp27.

Hsp27 protects cell death of PC12 cells and SCG neurons If ATF3 inhibits apoptosis by upregulating Hsp27, Hsp27 might have anti-apoptotic activity in PC12 cells and SCG neurons. In fact, previous studies show that adenoviral expression of Hsp27 
promotes the survival of SCG neurons from NGF withdrawal (Lewis et al., 1999) and peripheral nerve injury in neonates (Benn et al., 2002). In undifferentiated PC12 cells, Hsp27 overexpression alone by adenovirus did not affect the survival ratio in PC12 cells, but the overexpression significantly inhibited JNK-induced apoptosis in PC12 cells and SCG neurons (Fig. 7A). Hsp27 also induced neurite elongation in JNK-activated PC12 cells, whereas this neurite elongation could not be seen in Hsp27 expression without JNK activation (Fig. 7 B, C). Similarly, in SCG, Hsp27 expression clearly demonstrated rescue activities in the WST-8 assay (Fig. $7 \mathrm{Da}$ ) and in the histological assay (ratios of cells having pyknotic nuclei among infected cells) (Fig. 7 Db). Moreover, Hsp27 overexpression induced Akt phosphorylation in PC12 cells and SCG neurons (Fig. $7 E, F)$.

\section{Discussion}

In this study, we explored a novel function of ATF3 in neuronal survival and nerve regeneration, suggesting the possible existence of an ATF3/c-Jun-Hsp27 pathway and possibly leading to an Akt signal pathway.

ATF3 is designated as a stressinducible gene (Liang et al., 1996; Hai et al., 1999). ATF3 is also known as a transcriptional repressor (Chen et al., 1994) and is implicated in the cell death of some non-neuronal cells (Mashima et al., 2001; Zhang et al., 2001; Nawa et al., 2002). Several genes have been implicated as the targets of ATF3. ATF3 homodimer functions as a repressor for most of the target genes such as gadd153/Chop10, E-selectin, and phsophoenolpyruvate carboxylase (Chen et al., 1996; Hai and Hartman, 2001). However, the heterodimeric complex of ATF3 with c-Jun, for instance, has been demonstrated to function as a transcriptional activator (Hsu et al., 1992; Hai and Hartman, 2001). ATF3 binds to the AP-1 family, and its transcriptional activity differs according to its counterpart. ATF3, in combination with c-Jun, activates specific promoters containing $\mathrm{AP}-1$ and $\mathrm{CRE}$ sites, but in contrast, ATF3 in combination with JunB potently represses activation of these promoters (Hsu et al., 1992). In addition, Hai and colleagues proposed mechanisms by which ATF3 can perform the opposite functions of gene repression or activation (Chen et al., 1994). The functional consequence of ATF3 thus varies in stress signals and cell types. In adult CNS and PNS neurons, ATF3 was designated as a marker for nerve injury because of its specific expression in response to nerve injury (Takeda et al., 2000; Tsujino et al., 2000), activated by NGF withdrawal.
A
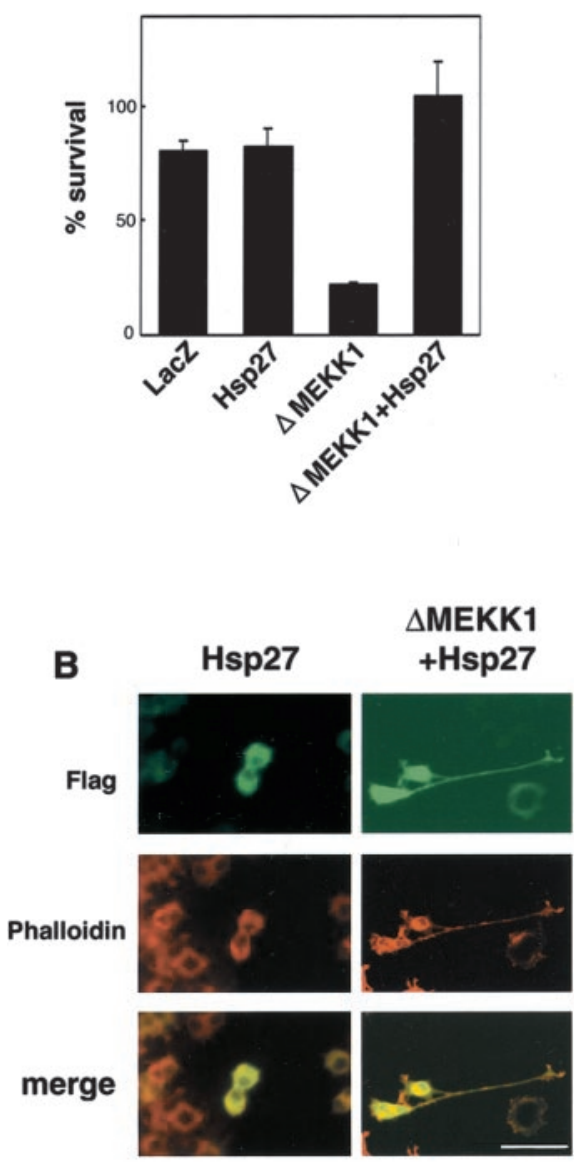

C

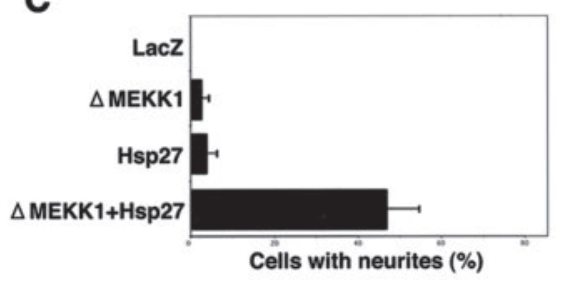

D

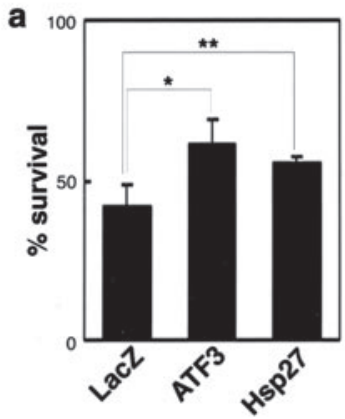

b
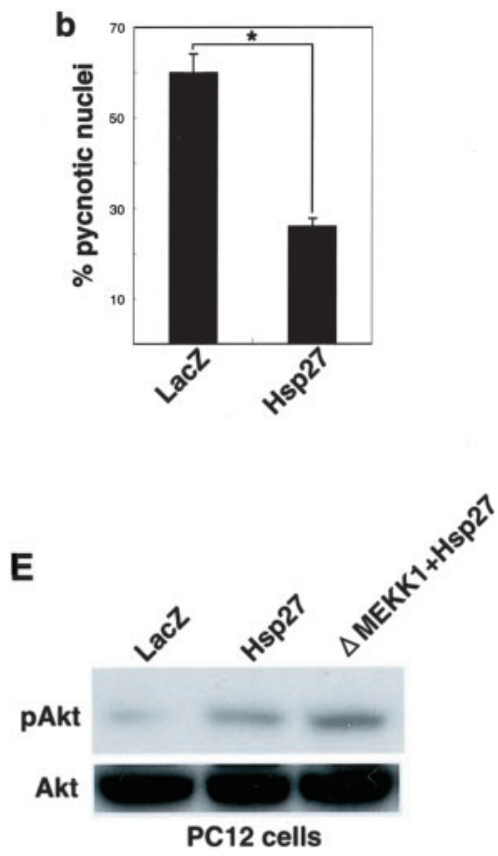

$\mathbf{F}$

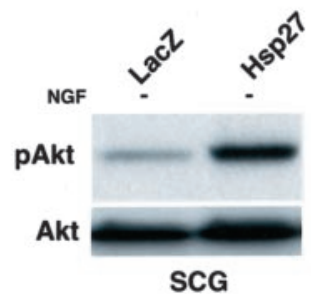

Figure 7. Hsp27 expression rescues $\mathrm{PC1} 12$ cells and SCG neurons from JNK-induced cell death and elicits neurite outgrowth. $A$, Viability of $\mathrm{PC} 12$ cells $48 \mathrm{hr}$ after adenovirus infection. Viability of adenovirus uninfected cells was defined as $100 \%$. Each column represents the average of values from four different experiments. $B$, Morphology of adenovirus-infected PC12 cells. Forty-eight hours after adenovirus infection, the cells were fixed, and infected cells were detected with anti-Flag antibody. Phalloidin conjugated with Alexa594 was used to visualize the cell shape. Scale bar, $20 \mu \mathrm{m}$. C, Quantification of neurite outgrowth. The percentage of the cells with neurite exceeding twice the cell body length among the infected cells is shown. D, $a$, Viability of $S C G$ neurons $48 \mathrm{hr}$ after NGF deprivation. Viability of SCG neurons cultured with NGF medium was defined as $100 \%$. Each column represents the average of values from four different experiments. ${ }^{*} p=0.01 ;{ }^{* *} p=0.05$ (Student's $t$ test). $b$, Twenty-four hours after NGF withdrawal, nuclear morphology of SCG neurons was visualized with Hoechst 33342, and pyknotic nuclei were counted among adenovirus-expressing cells visualized by anti-Flag or anti- $\beta$-galactosidase antibody. ${ }^{*} p=0.01$ (Student's $t$ test). $E, F$, Activation of Akt in PC12 cells (36 hr after adenovirus infection) and SCG neurons (24 hr after NGF withdrawal). In PC12 cells, phosphorylation of Akt was increased when ad-Hsp27 was infected. Further induction was also observed when both ad-Hsp27 and ad- $\triangle$ MEKK1 were coinfected. Phosphorylation of Akt was also increased in ad-Hsp27-infected SCG neurons, in which JNK was

although the functional consequences of ATF3 in nerve injury were not known. One of the major findings in this study is that ATF3 expression under the activation of JNK does show apparent rescue and neurite elongation activities in PC12 and SCG neu- 
rons. These ATF3-mediated regeneration activities are inhibited by a JNK inhibitor such as JIP(JBD). This result indicates that ATF3 needs JNK activation or other transcription factors activated by JNK possibly as a counterpart for transcriptional activation. Because the transcriptional activity of ATF3 differs according to its counterpart, the identification of the counterpart of ATF3 in neurons under stress could be crucial in revealing the functional consequences of ATF3. Among the downstream targets of JNK, c-Jun could be a feasible candidate as a counterpart of ATF3. It is well known that NGF deprivation activates c-Jun via JNK activation and causes apoptotic cell death in PC12 and SCG cells (Ham et al., 1995; Eilers et al., 1998). This suggests that c-Jun is activated in those cells under stress. In fact, the in vitro coimmunoprecipitation studies clearly demonstrated the possible binding of ATF3 and c-Jun, and in vivo coimmunolocalization studies support the possibility (Takeda et al., 2000; Tsujino et al., 2000). In addition, the fact that the dominant-negative c-Jun, c-Jun223NLS, repressed the ATF3-mediated activation of Hsp27 promoter also supports the significance of the combination of c-Jun and ATF3 in eliciting the survival function. The additional expression of ATF3 in those cells could neutralize the JNKmediated death signal and further elicit the anti-apoptotic response together with c-Jun. In this respect, overexpression or activation of ATF3 in neurons under JNK-derived apoptotic stress may be applicable to a potent therapeutic treatment for the neuronal death seen in brain ischemia and degenerative diseases.

The present DNA microarray study revealed that the molecular chaperone Hsp27, which is known to inhibit cell death in neuronal cells (Costigan et al., 1998; Lewis et al., 1999; Benn et al., 2002), is a transcriptional target of ATF3/c-Jun. We initially identified $\sim 50$ genes in the microarray study, but Hsp27 was the only gene derived from the second screening using in situ hybridization. Interestingly, the previous studies together with the present study demonstrate coexpression of Hsp27 and c-Jun or coexpression of Hsp27 and ATF3 in dorsal root ganglion (DRG) and motor neurons after nerve injury and in SCG neurons (Lewis et al., 1999; Benn et al., 2002). These colocalization studies also support the present result that ATF3/c-Jun induces Hsp27 expression. The present study further demonstrates that the atypical CRE motif located at -678 of Hsp 27 promoter is the target of ATF3/c-Jun. Previously it has been demonstrated that the activation of heat shock gene transcription during stress responses is mediated by a heat shock transcription factor (HSF), which binds to a heat shock element (HSE) in the promoters of the Hsp family (Wu, 1995). In fact HSE is also located around -200 of the Hsp27 promoter (Hickey et al., 1986). In our promoter analysis, neither ATF3 nor ATF3/JNK activation significantly altered HSEmediated expression of Hsp27. Therefore, ATF3-mediated expression of Hsp27 would be regulated mainly at the atypical CRE site. However, it should be mentioned that in our preliminary experiment, the deletion of HSE from the promoter significantly suppressed the expression level of Hsp27, which was induced by ATF3/c-Jun (our unpublished data). This suggests that not only ATF3/c-Jun but also HSF might be involved in Hsp27 expression.

Another intriguing finding in this study is that Hsp27 activates Akt by an as yet unknown mechanism. An ERK or Akt pathway, or both, is crucial for the survival of neurons under death stress, and growth factor receptors located upstream of these pathways are the major signal inputs for their activation. In regard to rescuing PC12 cells from NGF deprivation-derived apoptosis, either ERK or Akt activation is enough (Xia et al., 1995; Namikawa et al., 2000). ATF3 expression and JNK activation demonstrated the phosphorylation of Akt but not ERK, although no induction of the synthesis of these proteins was observed. This may suggest that the combination of ATF3/c-Jun induces expression of some molecules that might activate Akt. As shown in this study, Hsp27 can be induced by ATF3 and c-Jun, and in fact Hsp27 overexpression elicits Akt phosphorylation in PC12 and SCG neurons under stress. As for a mechanism underlying Hsp27-mediated neuronal survival, it is proposed that Hsp27 directly binds to cytochrome $c$ to inhibit the caspase pathway and protect cells from apoptosis (Saleh et al., 2000). In addition, the present study suggests another possible mechanism in which Hsp27 induces Akt activation and thereby elicits multiple survival responses (Datta et al., 1997; del Peso et al., 1997; Brunet et al., 1999). Interestingly, Hsp27 can bind to Akt and may have some role in its activation (Konishi et al., 1997). Hsp27 is not a kinase, and the kinases such as 3-phosphoinositide-dependent protein kinase (PDK), which phosphorylates Akt, may exist near the membrane (Anderson et al., 1998). Although the mechanism underlying Hsp27-mediated Akt phosphorylation is not clear, it may be likely that Hsp27 serves as a chaperone that translocates Akt to the cytoplasmic membrane where Akt is phosphorylated by PDK. Alternatively, Hsp27, as seen in Hsp90, may serve as a stabilizer for the maintenance of Akt activity (Sato et al., 2000). Hsp27 is phosphorylated after nerve injury, and this phosphorylation appears necessary for neuronal regeneration (Benn et al., 2002). Taking this into consideration, it is likely that an additional unknown molecule, which is the transcriptional target of ATF3/c-Jun and activates the phosphorylation of Hsp27, is needed to gain full activation of Hsp27 for neuronal survival. It should be mentioned that although Hsp27 overexpression is enough to promote Akt activation and survival activity, it is not sufficient for neurite elongation activity. For neurite elongation, JNK activation, in addition to Hsp27 expression, appears to give more efficient activity. It is possible that some other factors, which are regulated by the JNK/ SAPK pathway, are involved in the neurite elongation mechanism in addition to Hsp27.

In conclusion, our results demonstrate that the ATF3/c-JunHsp27 pathway, possibly leading to an Akt pathway, could be a novel survival response. The activation of Akt by this pathway is ATF3/cJun dependent and possibly growth factor receptor signaling independent, suggesting that this mechanism is an intrinsic response to death stress. When this pathway is activated by inducing ATF3 in neurons under JNK-mediated stress, it works well for survival in vitro. This also seems to work in vivo at least in injured motor neurons and DRG neurons, which survive and regenerate after nerve injury (Costigan et al., 1998; Lewis et al., 1999; Benn et al., 2002). In contrast, nerve-injured motor neurons in neonates do not express sufficient amounts of ATF3 or Hsp27, and this lack of endogenous response may lead those neurons to death. Therefore, those neonatal motor neurons and neurons under JNK-mediated stress may be rescued by promoting the activation of ATF3. This may provide a new therapeutic intervention aimed at rescuing degenerating neurons in brain ischemia and trauma.

\section{References}

Anderson KE, Coadwell J, Stephens LR, Hawkins PT (1998) Translocation of PDK-1 to the plasma membrane is important in allowing PDK-1 to activate protein kinase B. Curr Biol 8:684-691.

Benn S, Perrelet D, Kato A, Scholz J, Decosterd, Mannion R, Bakowska J, Woolf C (2002) Hsp27 upregulation and phosphorylation is required for injured sensory and motor neuron survival. Neuron 36:45-56.

Brunet A, Bonni A, Zigmond MJ, Lin MZ, Juo P, Hu LS, Anderson MJ, Arden KC, Blenis J, Greenberg ME (1999) Akt promotes cell survival by phosphorylating and inhibiting a Forkhead transcription factor. Cell 96:857-868. 
Chen BP, Liang G, Whelan J, Hai T (1994) ATF3 and ATF3 delta Zip. Transcriptional repression versus activation by alternatively spliced isoforms. J Biol Chem 269(22):15819-15826.

Chen BP, Wolfgang CD, Hai T (1996) Analysis of ATF3, a transcription factor induced by physiological stresses and modulated by gadd153/ Chop10. Mol Cell Biol 16:1157-1168.

Costigan M, Mannion RJ, Kendall G, Lewis SE, Campagna JA, Coggeshall RE, Meridith-Middleton J, Tate S, Woolf CJ (1998) Heat shock protein 27: developmental regulation and expression after peripheral nerve injury. J Neurosci 18:5891-5900.

Creedon DJ, Johnson EM, Lawrence JC (1996) Mitogen-activated protein kinase-independent pathways mediate the effects of nerve growth factor and cAMP on neuronal survival. J Biol Chem 271:20713-20718.

Datta SR, Dudek H, Tao X, Masters S, Fu H, Gotoh Y, Greenberg ME (1997) Akt phophorylation of BAD couples survival signals to the cell-intrinsic death machinery. Cell 91:234-241.

del Peso L, Gonzalez-Garcia M, Page C, Herrera R, Nunez G (1997) Interleukin-3-induced phosphorylation of $\mathrm{BAD}$ through the protein kinase Akt. Science 278:687-689.

Dickens M, Rogers JS, Cavanagh J, Raitano A, Xia Z, Halpern JR, Greenberg ME, Sawyers CL, Davis RJ (1997) A cytoplasmic inhibitor of the JNK signal transduction pathway. Science 277:693-696.

Eilers A, Whitfield J, Babij C, Rubin LL, Ham J (1998) Role of the Jun kinase pathway in the regulation of c-Jun expression and apoptosis in sympathetic neurons. J Neurosci 18:1713-1724.

Eilers A, Whitfield J, Shah B, Spadoni C, Desmond H, Ham J (2001) Direct inhibition of c-Jun N-terminal kinase in sympathetic neurones prevents c-jun promoter activation and NGF withdrawal-induced death. J Neurochem 76:1439-1454.

Fawcett JW, Geller HM (1998) Regeneration in the CNS: optimism mounts. Trends Neurosci 21:179-180.

Hai T, Curran T (1991) Cross-family dimerization of transcription factors Fos/Jun and ATF/CREB alters DNA binding specificity. Proc Natl Acad Sci USA 88:3720-3724.

Hai T, Hartman MG (2001) The molecular biology and nomenclature of the activating transcription factor/cAMP responsive element binding family of transcription factors: activating transcription factor proteins and homeostasis. Gene 273:1-11.

Hai T, Wolfgang CD, Marsee DK, Allen AE, Sivaprasad U (1999) ATF3 and stress responses. Gene Expr 7:321-335.

Hai TW, Liu F, Coukos WJ, Green MR (1989) Transcription factor ATF cDNA clones: an extensive family of leucine zipper proteins able to selectively form DNA-binding heterodimers. Genes Dev 3:2083-2090.

Ham J, Babij C, Whitfield J, Pfarr CM, Lallemand D, Yaniv M, Rubin LL (1995) A c-Jun dominant negative mutant protects sympathetic neurons against programmed cell death. Neuron 14:927-939.

Herdegen T, Skene P, Bahr M (1997) The c-Jun transcription factor-bipotential mediator of neuronal death, survival and regeneration. Trends Neurosci 20:227-231.

Hickey E, Brandon SE, Potter R, Stein G, Stein J, Weber LA (1986) Sequence and organization of genes encoding the human $27 \mathrm{kDa}$ heat shock protein. Nucleic Acids Res 14:4127-4145.

Honma M, Namikawa K, Mansur K, Iwata T, Mori N, Iizuka H, Kiyama H (2002) Developmental alteration of nerve injury induced glial cell linederived neurotrophic factor (GDNF) receptor expression is crucial for the determination of injured motoneuron fate. J Neurochem 82:961-975.

Hsu JC, Bravo R, Taub R (1992) Interactions among LRF-1, JunB, c-Jun, and c-Fos define a regulatory program in the G1 phase of liver regeneration. Mol Cell Biol 12:4654-4665.

Kanegae Y, Makimura M, Saito I (1994) A simple and efficient method for purification of infectious recombinant adenovirus. Jpn J Med Sci Biol 47:157-166.

Kanegae Y, Lee G, Sato Y, Tanaka M, Nakai M, Sakaki T, Sugano S, Saito I (1995) Efficient gene activation in mammalian cells by using recombinant adenovirus expressing site-specific Cre recombinase. Nucleic Acids Res 23:3816-3821.

Kitamura T, Ogawa W, Sakaue H, Hino Y, Kuroda S, Takata M, Matsumoto M, Maeda T, Konishi H, Kikkawa U, Kasuga M (1998) Requirement for activation of the serine-threonine kinase Akt (protein kinase B) in insulin stimulation of protein synthesis but not of glucose transport. Mol Cell Biol 18:3708-3717.

Konishi H, Matsuzaki H, Tanaka M, Takemura Y, Kuroda S, Ono Y, Kikkawa
U (1997) Activation of protein kinase B (Akt/RAC-protein kinase) by cellular stress and its association with heat shock protein Hsp27. FEBS Lett 410:493-498.

Leppa S, Saffrich R, Ansorge W, Bohmann D (1998) Differential regulation of c-Jun by ERK and JNK during PC12 cell differentiation. EMBO J 17:4404-4413.

Leppa S, Eriksson M, Saffrich R, Ansorge W, Bohmann D (2001) Complex functions of AP-1 transcription factors in differentiation and survival of PC12 cells. Mol Cell Biol (13):4369-4378.

Lewis SE, Mannion RJ, White FA, Coggeshall RE, Beggs S, Costigan M, Martin JL, Dillmann WH, Woolf CJ (1999) A role for HSP27 in sensory neuron survival. J Neurosci 19:8945-8953.

Liang G, Wolfgang CD, Chen BP, Chen TH, Hai T (1996) ATF3 gene. Genomic organization, promoter, and regulation. J Biol Chem 271:1695-1701.

Mashima T, Udagawa S, Tsuruo T (2001) Involvement of transcriptional repressor ATF3 in acceleration of caspase protease activation during DNA damaging agent-induced apoptosis. J Cell Physiol 188(3):352-358.

Miyake S, Makimura M, Kanegae Y, Harada S, Sato Y, Takamori K, Tokuda C, Saito I (1996) Efficient generation of recombinant adenoviruses using adenovirus DNA-terminal protein complex and a cosmid bearing the full-length virus genome. Proc Natl Acad Sci USA 93:1320-1324.

Nakagomi S, Kiryu-Seo S, Kimoto M, Emson PC, Kiyama H (1999) Dimethylarginine dimethylaminohydrolase (DDAH) as a nerve-injuryassociated molecule: mRNA localization in the rat brain and its coincident up-regulation with neuronal NO synthase (nNOS) in axotomized motoneurons. Eur J Neurosci 11:2160-2166.

Namikawa K, Honma M, Abe K, Takeda M, Mansur K, Obata T, Miwa A, Okado H, Kiyama H (2000) Akt/protein kinase B prevents injuryinduced motoneuron death and accelerates axonal regeneration. J Neurosci 20:2875-2886.

Nawa T, Nawa MT, Adachi MT, Uchimura I, Shimokawa R, Fujisawa K, Tanaka A, Numano F, Kitajima S (2002) Expression of transcriptional repressor ATF3/LRF1 in human atherosclerosis: colocalization and possible involvement in cell death of vascular endothelial cells. Atherosclerosis 161:281-291.

Saleh A, Srinivasula SM, Balkir L, Robbins PD, Alnemri ES (2000) Negative regulation of the Apaf-1 apoptosome by Hsp70. Nat Cell Biol 2:476-483.

Sato S, Fujita N, Tsuruo T (2000) Modulation of Akt kinase activity by binding to Hsp90. Proc Natl Acad Sci USA 97:10832-10837.

Sato Y, Tanaka K, Lee G, Kanegae Y, Sakai Y, Kaneko S, Nakabayashi H, Tamaoki T, Saito I (1998) Enhanced and specific gene expression via tissue-specific production of Cre recombinase using adenovirus vector. Biochem Biophys Res Commun 244:455-462.

Takeda M, Kato H, Takamiya A, Yoshida A, Kiyama H (2000) Injuryspecific expression of activating transcription factor-3 in retinal ganglion cells and its colocalized expression with phosphorylated c-Jun. Invest Ophthalmol Vis Sci 41 2412-2421.

Tawadros T, Formenton A, Dudler J, Thompson N, Nicod P, Leisinger HJ, Waeber G, Haefliger JA (2002) The scaffold protein IB1/JIP-1 controls the activation of JNK in rat stressed urothelium. J Cell Sci 115:385-393.

Terashima T, Miwa A, Kanegae Y, Saito I, Okado H (1997) Retrograde and anterograde labeling of cerebellar afferent projection by the injection of recombinant adenoviral vectors into the mouse cerebellar cortex. Anat Embryol (Berl) 196:363-382.

Treier M, Staszewski LM, Bohmann D (1994) Ubiquitin-dependent c-Jun degradation in vivo is mediated by the delta domain. Cell 78(5):787-798.

Tsujino H, Kondo E, Fukuoka T, Dai Y, Tokunaga A, Miki K, Yonenobu K, Ochi T, Noguchi K (2000) Activating transcription factor 3 (ATF3) induction by axotomy in sensory and motoneurons: A novel neuronal marker of nerve injury. Mol Cell Neurosci 15:170-182.

Wu C (1995) Heat shock transcription factors: structure and regulation. Annu Rev Cell Dev Biol 11:441-469.

Xia Z, Dickens M, Raingeaud J, Davis RJ, Greenberg ME (1995) Opposing effects of ERK and JNK-p38 MAP kinases on apoptosis. Science 270:1326-1331.

Zhang C, Kawauchi J, Adachi MT, Hashimoto Y, Oshiro S, Aso T, Kitajima S (2001) Activation of JNK and transcriptional repressor ATF3/LRF1 through the IRE1/TRAF2 pathway is implicated in human vascular endothelial cell death by homocysteine. Biochem Biophys Res Commun 289(3):718-724. 